\title{
Tinjauan Pengelolaan Data Berbasis Digital Bagian Registrasi Pendaftaran Di RSUP Haji Adam Malik Medan
}

\author{
Puput Melati Hutauruk ${ }^{1}$, Khairani ${ }^{2}$ \\ ${ }^{1}$ Program Studi D-IV Manajemen Informasi Kesehatan, Universitas Imelda Medan \\ ${ }^{2}$ Program Studi D-3 Perekam dan Informasi Kesehatan, Universitas Imelda Medan
}

\begin{tabular}{l} 
Article Info \\
\hline Article history: \\
Received Dec 30, 2020 \\
Revised Feb 24, 2021 \\
Accepted Feb 25, 2021 \\
\hline
\end{tabular}

\section{Keywords:}

Management Elements Digitalization Data Manage

\begin{abstract}
ABSTRAK
Data management is a data place that will become information which will later become health information. Where patient registration if done manually will be slow automatic management of data will have an impact on the quality of hospital services. Therefore digitization is required. The purpose of this study was to see how the implementation of digital-based data management. Subjects in this study were registration officers who entered 7 people, with the object being not 5M. This research was conducted with a descriptive method with a qualitative approach. Instrumentation of interview data and observation checklist. With the TOTAL 3 informants. The data analysis is descriptive qualitative to describe the implementation of data management. Based on the results of the research that there is no one who is not competence, the money is not yet available and adequate, the method is appropriate but has not worked well, the machine is not as expected while the material is in accordance with the competence. Suggestions from researchers are that officers should distribute leaflets (paper leaflets) to the public so that the public can register via cellphones (cellular) and that officers should change the internet speed to MBPS so that the registration process does not occur sluggishly.
\end{abstract}

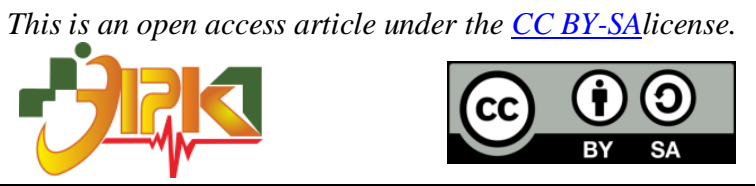

Corresponding Author:

Puput Melati Hutauruk,

Program Studi D-IV Manajemen Informasi Kesehatan,

Universitas Imelda Medan,

Jl. Bilal No. 52 Kelurahan Pulo Brayan Darat I Kecamatan Medan Timur, Medan - Sumatera Utara.

Email: puputmelati.pm71@gmail.com

\section{PENDAHULUAN}

Perkembangan teknologi informasi telah menyebar hampir keseluruh bidang. Salah satunya pada rumah sakit yang merupakan penyedia jasa kesehatan yang memberikan pelayanan perorangan secara paripurna dan yang menyediakan pelayanan baik instalasi rawat inap maupun rawat jalan serta gawat darurat (Permenkes RI, 2018).

Salah satu cara meningkatkan kualitas pada pelayanan kesehatan adalah dengan meningkatkan kualitas rekam medis. Secara garis besar dokumen/status rekam medis adalah catatan yang berisikan rekaman informasi kesehatan pasien. Sebelum menjadi sebuah informasi data pada berkas rekam medis pasien tersebut dikelola terlebih dahulu 
atau dengan kata lain dilakukan pengelolaan data. Salah satu tempat pengelolaan data adalah pendaftaran, dimana pendaftaran pasien jika dilakukan secara manual akan mengakibatkan lambatnya pengelolaan data yang otomatis berdampak kepada mutu pelayanan rumah sakit maka karena itu digitalisasi menjadi sangat diperlukan.

Berdasarkan hal tersebut muncul pengertian bahwa digitalisasi merupakan proses konversi dari segala bentuk fisik atau analog kedalam bentuk digital (Atmoko, 2015). Dengan kata lain digitalisasi merupakan media baru yang telah beralih dari yang bersifat manual beralih ke otomatis, dari segala yang bersifat sulit menjadi cepat serta berubahnya cara kerja. Berbeda dengan komputerisasi, yang hanya untuk menggantikan mesin analog. Namun cara kerja masih sama seperti ketika komputer belum ada. Dengan menerapkan digitalisasi semua pemberi pelayanan kesehatan tidak lagi menggunakan berkas rekam medis dalam bentuk kertas kecuali untuk hal yang terkait dengan hukum.

Dari hasil penelitian (Annisa, 2019) di Rumah Sakit Pantiwilasa Citarum Semarang bahwa pengelolaan data khusus pendaftaran di Rumah Sakit Pantiwilasa Citarum Semarang sudah berbasis digital dimana proses pendaftarannya menggunakan aplikasi online RSPWC Mobile. Menurut annisa pasien yang menggunakan aplikasi tersebut merasa tidak rumit dan cukup fleksibel digunakan namun masih ada pasien menyatakan kesulitan menerima aplikasi RSPWC Mobile karena tidak tersedianya layanan untuk bertanya dan mengeluhkan banyaknya berkas yang harus diupload serta merasa masih membutuhkan rentan waktu yang lama saat melakukan pendaftaran online melalui aplikasi tersebut. Hal ini juga berdampak kepada petugas yang menginput data pasien karena menjadi lebih lama dalam memproses atau mengolah data.

Berdasarkan survey pendahuluan pelaksanaan pengelolan data khusus pendaftaran di RSUP. H. Adam Malik bahwa pengelolaan data bagian pendaftaran sudah menggunakan PC (personal computer) dan jaringan internet. Namun yang menjadi permasalahan ditemukan terjadi beberapa kali jaringan lemot dan error pada saat melakukan proses pengelolan data hal ini mengakibatkan terganggunya proses pengelolaan data. Oleh karena itu penulis tertarik mengambil judul tentang Tinjauan Pengelolaan data berbasis digital di RSUP. H. Adam Malik tahun 2020.

Rumusan Masalah pada penitian ini adalah "Bagaimana Pelaksanaan Pengelolaan Data berbasis Digital?. Adapun tujuan penelitian adalah untuk mengetahui tentang bagaimana pelaksanaan pengelolaan data berbasis digital khusus pendaftaran di RSUP. H. Adam Malik medan. Manfaat Peneliti Bagi Peneliti adalah menambah pengetahuan serta pengalaman mahasiwa khususnyadalam pelaksanaan pengelolaan data berbasis digital rekam medis, bagi Rumah Sakit, Sebagai referensi masukan dalam pelaksanaan pengelolaan data berbasis digital. Bagi Akademi Menambah bahan pertimbangan dalam melakukan penelitian lebih lanjut.

\section{METODE PENELITIAN}

A. Jenis Penelitian

Yaitu penelitian deskriptif kualitatif yang memiliki karakteristik bersifat deskriptif. teori yang digunakan dalam penelitian tidak dipaksakan untuk memperoleh gambaran seutuhnya mengenai suatu hal menurut pandangan yang diteliti (Sulistyo-Basuki, 2006).

B. Waktu dan Tempat Penelitian

Penelitian ini dilaksanakan di Rumah Sakit Umun Haji Adam Malik Medan, di bagian instalasi rekam medis khususnya bagian pendaftaran pada bulan Juli Agustus Tahun 2020. 
C. Subyek dan Objek Penelitian

- Subjek

Adapun subjek dalam penelitian ini adalah petugas rekam medis bagian pendaftaran yang berjumlah sebanyak 3 orang.

- Objek Penelitian

Menurut (Sugiyono, 2017) menjelaskan pengertian objek penelitian adalah "sasaran ilmiah untuk mendapatkan data dengan tujuan dan kegunaan tertentu tentang sesuatu hal objektif yang valid. Objek dalam penelitian ini adalah pengelolaan data di RSUP H. Adam Malik Medan.

D. Definisi Operasional

- Variabel Peneliti

Variabel dalam penelitian ini adalah unsur 5M yaitu man, money, methode, machine, material.

- Definisi Operasional

Definisi operasional menurut Notoatmodjo (2012), merupakan uraian tentang batasan variabel yang dimaksud, atau tentang apa yang diukur oleh variabel yang bersangkutan.

Tabel 1. Variabel dan DO

\begin{tabular}{|c|c|}
\hline Variabel Penelitian & Definisi Operasional \\
\hline Man & $\begin{array}{l}\text { Man merupakan sumber manusia yang berperan dalam } \\
\text { melakukan proses kegiatan pengelolaan data berbasis digital } \\
\text { khusus pendaftaran di RSU. H. Adam Malik Medan. }\end{array}$ \\
\hline Money & $\begin{array}{l}\text { Money merupakan alat tukar berupa anggaran yang digunakan } \\
\text { untuk melengkapi keperluan dalam menunjang pengelolaan data } \\
\text { berbasis digital khusus pendaftaran di RSU .H. Adam Malik } \\
\text { Medan. }\end{array}$ \\
\hline Method & $\begin{array}{l}\text { Methode merupakan tata cara kerja dalam pengelolaan data } \\
\text { berbasis digital khusus pendaftaran di RSU. H. Adam Malik } \\
\text { Medan. }\end{array}$ \\
\hline Machine & $\begin{array}{l}\text { Machine atau mesin digunakan untuk mempermudah pengerjaan } \\
\text { pengelolaan data berbasis digital khusus pendaftaran di RSU. H. } \\
\text { Adam Malik Medan }\end{array}$ \\
\hline Material & $\begin{array}{l}\text { Material merupakan bahan atau peralatan yang diperlukan } \\
\text { dalam kegiatan pengelolaan data berbasis digital khusus } \\
\text { pendaftaran di RSU. H. Adam Malik Medan. }\end{array}$ \\
\hline
\end{tabular}

E. Instrumen dan Cara Pengumpulan Data

- Instrumen Penelitian

Intrument penelitian adalah alat-alat yang digunakan untuk pengumpulan data (Notoatmodojo, 2010). Maka Instrumen penelitian di RSU. H. Adam Malik ini adalah wawancara dan observasi dengan 3 responden.

- Cara Pengumpulan Data

1. Data Primer

Data primernya adalah data yang diperoleh secara langgsung dari petugas rekam medis melalui wawancara dan observasi.

2. Data Sekunder

Data sekunder adalah data yang diperoleh penelititi dari sumber yang sudah ada.Yang menjadi data sekunder di RSUP H.Adam Malik Medan adalah SOP yang ada di rumah sakit. 
F. Teknik Pengolahan dan Analisis Data

- Teknik Pengolahan Data

Teknik analisis yang digunakan pada penelitian ini yaitu dilakukan melaui 3 alur sebagai berikut:

1. Reduksi data

Reduksi data merupakan memilah hal-hal yang paling penting, dan memfokuskan pada hal-hal yang penting. Setelah itu data yang telah direduksi akan menunjukaan gambaran yang lebih detail serta mempermudah peneliti.

2. Penyajian data

Penyajian data yaitu beberapa informasi yang menunjukkan kemungkinan adanya gambaran kesimpulan dan pengambilan tindakan. Data wawancara dan observasi disajikan dalam bentuk narasi.

2. Verifikasi data

Verifikasi data yaitu menarik kesimpulan berdasarkan hasil temuan dan data yang didapatkan selama penelitian.

- Analisis Data

Yaitu data yang diperoleh dari hasil wawancara, catatan lapangan, dan dokumentasi dengan cara mengorganisasikan data kedalam kategori, menjabarkan kedalam unit-unit (sugiyono, 2015). Berdasarkan hal tersebut, analisis data ini adalah deskriptif kualitatif unutuk menggambarkan pelaksanaan pengelolaan data di RSU. H. Adam Malik Medan.

\section{HASIL DAN PEMBAHASAN}

\subsection{Hasil}

Dari hasil penelitian yang dilakukan pada bulan Juli-Agustus Tahun 2020 kepada petugas pengelolaan data khusus pendaftaran rekam medis di RS. H Adam Malik diperoleh hasil sebagai berikut:

\section{Pengelolaan Data Berbasis Digital Pada Unsur Man}

Berdasarkan hasil wawancara yang dilakukan peneliti bahwa jumlah seluruh sumber daya manusia dalam pengolahan rekam medis khusus pendaftaran berjumlah sebanyak 7 orang diantaranya 4 orang berpendidikan rekam medis, 2 orang berlatar belakang pendidikan D3 keperawatan dan 1 orang belatar belakang pendidikan D3 gizi.

Tabel 2. Karakteristik Informan

\begin{tabular}{ccc}
\hline Petugas pendaftan & Jenis kelamin & Pendidikan \\
\hline Informan 1 & Laki- laki & D III Rekam Medis \\
\hline Informan 2 & Perempuan & D III Rekam Medis \\
\hline Informan 3 & Perempuan & D III Rekam Medis \\
\hline Informan 4 & Perempuan & D III Rekam Medis \\
\hline Informan 5 & Perempuan & D III Keperawatan \\
\hline Informan 6 & Perempuan & D III Keperawatan \\
\hline Informan 7 & Perempuan & D III Gizi \\
\hline
\end{tabular}

Dari hasil wawancara dan observasi diketahui petugas masih berinteraksi secara langgsung dengan pasien. Sedangkan SDM di bagian pendaftaran belum mencukupi karna jumlah pasien yang cukup banyak sesuai dengan ungkapan informan penelitian sebagai berikut "SDM di pendaftaran sekitar 7 orang, sementara pasien dalam sehari bisa ratusan bahkan lebih dek tapi pendaftaran udah bisa diakses lewat aplikasi di hp jadi pelayanan kami terbantu dan kami bisa melayani dengan baik." (informan 1,2,3) 
Berdasarkan hasil wawancara diketahui bahwa petugas sudah memiliki pengalaman menggunakan komputer sesuai dengan ungkapan dari informan sebagai berikut "iya, ada dek dulu waktu kuliah juga belajar komputer soalnya" (Informan 1,2,3).

\section{Pengelolaan Data Berbasis Digital Pada Unsur Money}

Hasil wawancara dan observasi yang dilakukan oleh peneliti bahwa dana tersedia dan tidak ada kendala.Tersedianya dana untuk keadaan darurat sedangkan pendanaan yang dikeluarkan oleh pihak rumah sakit yaitu pada sistem pengembangan seperti pembuatan aplikasi mobile untuk pendaftaran online dan adanya pendanaan yang dikeluarkan untuk jaringan internet serta spanduk pendaftaran online yang berada di dinding depan kursi tunggu pasien. Hal ini sesuai dengan pernyataan informan sebagai berikut: "untuk dana ada sih untuk keadaan darurat trus untuk pengeluaran ada juga untuk buat aplikasi pendaftaran online, spanduknya sama dana untuk jaringan internetnya dek."(informan $1,2,3)$.

\section{Pengelolaan Data Berbasis Digital Pada Unsur Methode}

Berdasarkan hasil wawancara dan observasi yang diperoleh dengan informan, pengelolaan unit rekam medis bagian pendaftaran berdasarkan unsur methods (metode) diketahui bahwa sistem pendaftaran di RSUP H.Adam Malik Medan memiliki dua sistem pendaftaran. Sistem pendaftran secara langsung dan sistem pendaftaran secara online (mobile). Hal ini sesuai dengan ungkapan informan yaitu sebagai berikut: "sistem pendaftaran disini dua dek, satu yang langgsung datang kerumah sakit satu lagi daftar lewat aplikasi di handphone, tapi lebih banyak yang daftar secara langgsung. "(Informan $1,2,3)$.

Berdasarkan hasil observasi bahwa sudah adanya SOP untuk pendaftaran online di RSUP H. Adam Malik Medan yang berjudul pendaftaran pasien rawat jalan online dengan nomor dokumen 572 yang disahkan pada tanggal 26 januari tahun 2018.

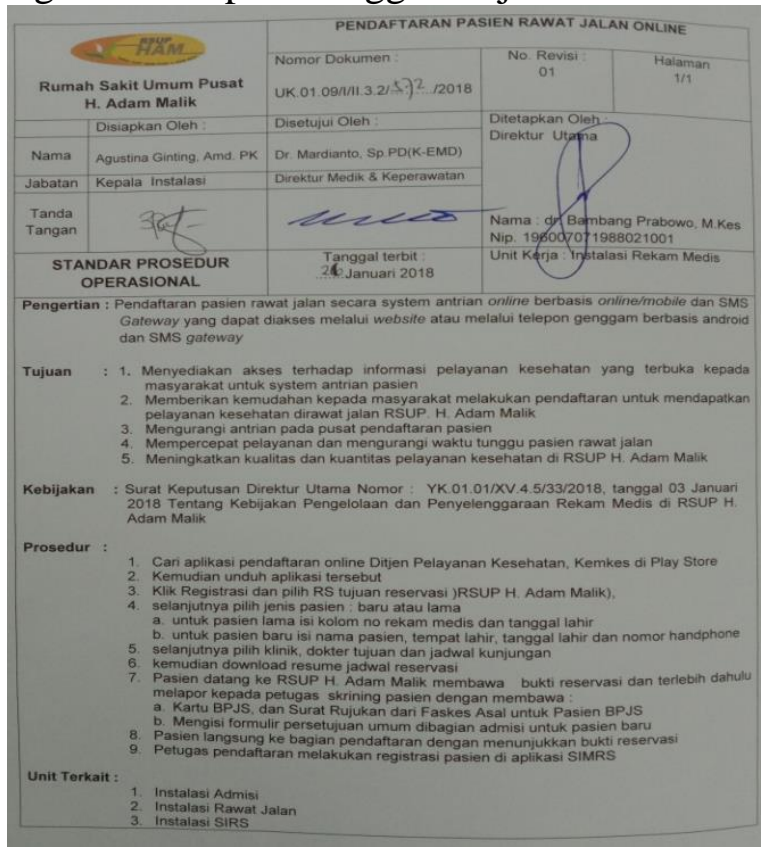

\section{Gambar 1. SOP Pendaftaran Pasien Rawat Jalan Online}

Berdasarkan SOP tersebut diketahui bahwa salah satu tujuan dari standar operasional prosedur di RSU H. Adam Malik Medan adalah mengurangi antrian pada pusat pendaftaran pasien namun berdasarkan hasil observasi diketahui bahwa masih banyaknya pasien yang menunggu. 


\section{Pengelolaan Data Berbasis Digital Pada Unsur Mechine}

Berdasarkan wawancara dengan informan penelitian, ketersediaan mechine di RM sudah memadai, seperti sudah tersedianya sinyal listrik, sudah tersedianya PC (personal computer) pada setiap petugas pendaftaran serta sudah tersedianya jaringan internet unlimitied dengan kecepatan 215 Mbps. Sesuai dengan ungkapan informan yaitu sebagai berikut: "iyaa, udah tersedianya computer, jaringan internet sama sinyal listrik." (informan 1, 2, 3 ).

Namun pada jaringan internet terjadi beberapa kali jaringan lemot dan error pada saat melakukan proses pengelolaan data sesuai dengan ungkapan informan yang di wawancarai sebagai berikut: "kalo jaringan sih kadang mau lemot dek sama error juga kadang".

\section{Pengelolaan Data Berbasis Digital Pada Unsur Material}

Berdasarkan hasil wawancara dan observasi bahwa sudah tersedianya material atau bahan di pengelolaan data bagian pendaftaran diantaranya adalah aplikasi pendaftaran online dan banner atau spanduk yang berisikan proses pendaftaran online. Hal ini telah sesuai dengan ungkapan responden sebagai berikut: "aplikasi pendaftaran online udah ada dibuat diandroid namanya pendaftaran online kalo spanduk ada di dinding dekat pendaftaran".

Aplikasi pendaftaran online tersebut dapat diunduh melalui smartphone dengan menggunakan nama aplikasi yaitu pendaftaran online sebagai berikut:

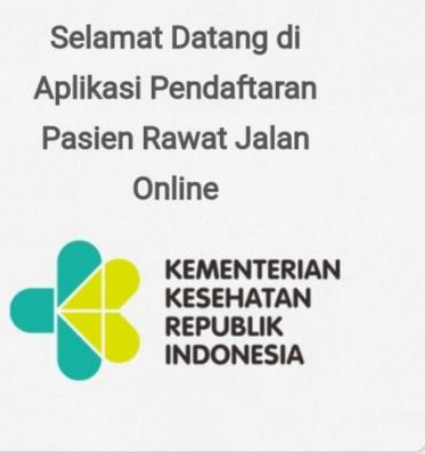

\section{Gambar 2. Apliksi Pendaftaran Pasien Rawat Jalan Online}

Berdasarkan hasil observasi dilapangan diketahui bahwa sudah tersedianya beberapa banner (spanduk) pendaftaran online yang terdapat didinding bagian pendaftaran rumah sakit. Spanduk tersebut berisikan cara atau langkah untuk melakukan pendaftaran pasien rawat jalan online melalui aplikasi pada android.

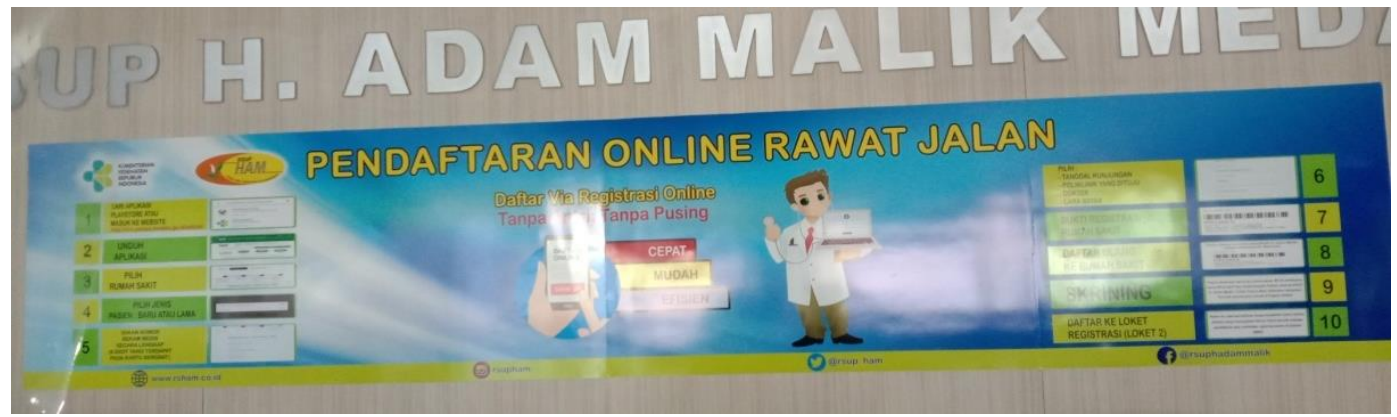

Gambar 3. Banner Aplikasi Pendaftaran Pasien Rawat Jalan Online 


\subsection{Pembahasan}

\section{Unsur Man Dalam Pengelolaan Data Berbasis Digital}

Berdasarkan dari hasil observasi maka yang menjadi man (sumber daya manusia) dalam unsur tersebut adalah petugas bagian pendaftaran yang berjumlah 7 orang. Diantaranya 4 Petugas tersebut sudah memiliki latar belakang pendidikan terakhir D3 Rekam Medis, 2 latar belakang D3 Keperawatan dan 1 orang berlatar pendidikan D3 Gizi 3 tetapi yang menjadi informan pada penelitian berjumlah 3 orang. Sehingga ketiga orang tersebut seluruhnya telah memiliki pengalaman dalam penggunaan komputer ketika masih kuliah sehingga diketahui petugas belum mengoperasikan komputer secara baik dan proses pendaftaran yang dikerjakan petugas menjadi lebih ringkas hal ini telah sesuai berdasarkan PERMENKES no. 377 yang dimana salah satu kompetensi D3 Perekam Medis adalah petugas mampu menggunakan aplikasi komputer untuk pengumpulan dan penyajian informasi kesehatan (permenkes, 2007).

Berdasarkan hasil penelitian yang dilakukan bahwa sistem pendaftaran di RSUP H. Adam Malik Medan ada dua yaitu secara langgsung dan secara mobile hal ini diakibatkan oleh pasien belum memahami sistem mobile. Berdasarkan indikator digitalisasi bagian pendaftaran bahwa salah satu petugasnya tidak lagi berinteraksi dengan pasien sedangkan hasil observasi yang dilakukan petugas masih ada interaksi dengan pasien oleh karena itu pengelolaan data berbasis digital dibagian pendaftaran belum sepenuhnya dapat dimanfaatkan secara maksimal oleh pasien.

\section{Unsur Money Dalam Pengelolaan Data Berbasis Digital}

Money merupakan point yang tidak pernah diabaikan. Hal ini dikarenakan uang adalah alat tukar dan alat pengukur nilai besar kecilnya hasil kegiatan yang hanya dapat diukur dari jumlah uang yang beredar. Berdasarkan hasil observasi yang diperoleh dari RSUP H. Adam Malik Medan bahwa terdapat adanya biaya atau dana yang dikeluarkan dalam kegiatan pengoperasian digital yaitu dana pengembangan pembuatan aplikasi mobile untuk pendaftaran online, adanya pendanaan yang dikeluarkan untuk jaringan internet serta dana yang dikeluarkan untuk spanduk pendaftaran online. Hal ini telah sesuai dengan menurut (Anang dan Budi, 2018) bahwa diperlukannya anggaran dalam pelaksanaan rekam medis untuk meningkatkan kualitas pelayanan pasien.

\section{Unsur Methode Dalam Pengelolaan Data Berbasis Digital}

Terdapatnya SOP (standar prosedur) yang berjudul pendaftataran pasien rawat jalan online dengan nomor dokumen 572 yang disahkan pada tanggal 26 januari tahun 2018. Bedasarkan hasil wawancara yang diperoleh bahwa SOP sudah berjalan dengan baik. Namun berdasarkan hasil observasi yang dilakukan di lapangan bahwa masih terdapat pasien yang menunggu antrian di tempat tunggu pendaftaran hal ini belum sesuai dengan menurut (Ekotama, 2015). Menurut peneliti bahwa perlu dibagikannya leafleat atau selebaran kertas kepada pasien agar pasien dapat mengetahui adanya pendaftaran yang dilakukan secara digital dengan melalui handphone. Sehingga pasien dapat mendaftar melalui mobile tanpa harus datang kerumah sakit, dengan hal ini waktu tunggu pasien akan berkurang.

\section{Unsur Mechine Dalam Pengelolaan Data Berbasis Digital}

Mesin digunakan untuk memberi kemudahan atau menghasilkan keuntungan yang lebih besar. Berdasarkan hasil observasi diperoleh dari RSU H. Adam Malik bahwa sudah tersedianya mesin dalam menunjang pengoperasian pengelolaan data berbasis digital diantaranya yaitu jaringan internet unlimitied dengan kecepatan 215 Mbps. Jaringan internet berfungsi sebagai jaringan pintar yang menjalankan aplikasi pendaftaran, 
komputer berfungsi sebagai mesin yang digunakan untuk mengelola data, sedangkan listrik dipakai untuk menghidupkan komputer dan lainnya. Namun dari hasil wawancara diketahui bahwa terjadi beberapa kali jaringan lemot dan error pada saat pengelolaan data akibatnya terganggunya proses penginputan data. Hal ini belum sesuai dengan teori Rusdarti bahwa mesin digunakan untuk memberi kemudahan dan menghasilkan keuntungan yang lebih besar sehingga dapat menciptakan efesiensi kerja (Rusdarti, 2008).

\section{Unsur Material Dalam Pengelolaan Data Berbasis Digital}

Berdasarkan penelitian ketersediaan material atau bahan pengelolaan data berbasis digital di unit rekam di RSUP H. Adam Malik Medan diperoleh bahwa sudah sudah tersedianya aplikasi pendaftaran online yang dapat diunduh melalui handphone, tersedianya banner (spanduk) yang berisikan tata cara atau langkah-langkah mendaftar pasien rawat jalan secara online di android. Letak spanduk tersebut berada pada dinding didepan tempat tunggu pasien didekat pendaftaran. Hal ini sudah sesuai dengan teori Rusdarti bahwa manusia tanpa bahan dan perlengkapan tidak akan mencapai tujuan yang diharapkan (Budi, 2011).

Namun tidak tersedianya leaflet atau selebaran kertas yang dibagikan kepada masyarakat untuk menginformasikan bahwa rumah sakit memiliki aplikasi pendaftaran online yang dapat diakses melalui android. Menurut peneliti bahwa perlu dibagikannya leafleat atau selebaran kertas kepada pasien agar pasien dapat mengetahui adanya pendaftaran yang dilakukan secara digital dengan melalui handphone. Sehingga pasien dapat mendaftar melalui mobile tanpa harus datang kerumah sakit, dengan hal ini waktu tunggu pasien akan berkurang.

\section{KESIMPULAN}

Berdasarkan hasil penelitian mengenai tinjauan pengelolaan data berbasis digital diperoleh kesimpulan sebagai berikut:

1. Unsur Man dalam pengelolaan rekam medis secara digital sudah sesuai dengan kompetensi yang dimana petugas pendaftaran dapat menggunakan komputer dan masih berinteraksi secara langgsung meski sudah dapat mengoperasikan aplikasi dengan menggunakan komputer.

2. Unsur Money dalam pengelolaan rekam medis secara digital sudah sesuai dimana adanya biaya atau dana yang dikeluarkan untuk kegiatan digitalisasi.

3. Unsur Methode dalam pengelolaan data di bagian pendaftaran sudah sesuai dengan kompetensi dimana sudah terdapatnya SOP pengelolaan data bagian pendaftaran secara digitalisasi namun belum berjalan dengan baik.

4. Unsur Machine dalam pengelolaan data di bagian pendaftaran sudah adanya mesin yaitu PC (personal computer), sinyal listrik dan jaringan internet, namun terjadi beberapakali lemot pada jaringan serta error dalam pengelolaan data oleh karena itu hal ini belum sesuai dengan yang diharapkan.

5. Unsur Material pengelolaan rekam medis sudah sesuai dengan kompetensi dimana sudah tersedianya bahan seperti handphone, aplikasi (software) banner (spanduk) yang diperlukan dalam kegiatan pengoperasian digitalisasi.

\section{REFERENCES}

Annisa. (2019). Analisis Penggunaan Aplikasi Pendaftaran Online RSPWC MOBILE Dalam Perspektif Kompleksitas Pada Pasien BPJS Rawat Jalan di Rumah Sakit Pantiwilasa Citarum Semarang. Jurnal Kesehatan Mayarakat, 6. 
Atmoko, Pitoyo Widhi. 2015. Digitalisasi dan Alih Media. Malang: Universitas Bramelati.

Arikunto, Suharsimi. 2016. Prosedur Penelitian: Suatu Pendekatan Praktik. Jakarta: Rineka Cipta

Anang M dan Budi W. 2018. Pengantar Manajemen. Edisi ke-1. Yogyakarta: Deepublish.

Adiputra, W. M. 2010. Potret Manajemen Media di Indonesia. Yogyakarta: Total Media.

Budi, S. C. 2011. Manajeen Unit Kerja Rekam Medis. Yogyakarta: Quantum Sinergis Media.

Basuki, Sulistyo. 2006. Metode penelitian. Jakarta: Wedatama Wedatama Widya Satra.

Departemen Kesehatan Republik Indonesia. 2018. Peraturan Mentri Kesehatan RI No. 4 tahun 2018. Kewajiban Rumah Sakit dan Kewajiban Pasien. Jakarta: Kemenkes RI

Departemen Kesehatan Republik Indonesia.2008. Peraturan Mentri Kesehatan No.269/MENKES/PER/III/2008. Rekam Medis. Jakarta: Kemenkes RI

Ekotama, S. 2015. Pedoman Mudah Menyusun SOP, Yogyakarta: MedPress.

Terry, George R.2012. Prinsip-Prinsip Manajemen. Jakarta: Bumi Aksara.

Menkes RI. 2014. Peraturan Menteri Kesehatan RI Nomor 92 tahun 2014 tentang Penyelenggaraan Komunikasi Data Dalam Sistem Informasi Kesehatan Terintegrasi.

Mulyatiningsi, Endang. 2011. Metode Penelitian Terapan Bidang Pendidikan. Bandung: Alfabeta.

MenKes. 2007. Keputusan Mentri Kesehatan Republik Indonesia Nomor: 377/Menkes/SK/III/2007 Tentang Standar Profesi Perekam Medis dan Informasi Kesehatan. Jakarta.

Notoatmodjo, Soekidjo. 2010. Metode Penelitian Kesehatan. Jakarta : Rineka Cipta.

Notoadmojo, Soekidjo. 2012. Promosi kesehatan dan perilaku kesehatan. Jakarta.

Nurdin I Hartati, S. 2019. Metodelogi Penelitian social. Diakses 3 july 2020. https://books.google.com/books/about/METODOLOGI_PENELITIAN_SOSIAL.html $? \mathrm{hl}=\mathrm{id} \& \mathrm{id}=$ tretDwAAQBAJ

Petrescu, Maria. 2008. Digitasation of Cultural Dokument. Philobiblon: Transylvanian journal of Multidisciplinary Research in Humanities 13, 550. Library, information science \& technology Abstract with full Text EBSC host.

Sugiharto, Dhani. 2010. Penyelamatan Informasi Dokumen/Arsip di Era Teknologi Digital Jurnal Pusat Dokumentasi dan Informasi LIPI.ANTRI: Jakarta. Sumber <http://pdii.lipi.go.id/baca/index.php/baca/aricle/view/96)> Diunduh $[21$ Agustus 2020] 
Sugiyono. (2017). Metode Penelitian Kuantitatif, Kualitatif, dan R\&D. Bandung: Alfabeta.

Sugiyono. 2012. Metode Penelitian Bisnis. Bandung: Alfabeta.

Sugiyono. 2015. Metode Penelitian Kuantitatif, dan R\&D. Bandung: Alfabeta.

Satrianegara, M. Fais. 2009. Buku Ajar Organisasi Dan Manejemen Pelayanan Kesehatan Serta Kebidanan. Jakarta: Salemba Medika.

Usman, Husaini. (2009). Manajemen: Teori, Praktik, dan Riset Peendidikan. Jakarta: Bumi Aksara.

\section{BIOGRAPHIES OF AUTHORS}

\begin{tabular}{|l|l|} 
& $\begin{array}{l}\text { Puput Melati Hutauruk, Gelar Sarjana diperoleh dari Universitas Sari Mutiara } \\
\text { Indonesia, Jurusan Administrasi Kebijakan Kesehatan (AKK) pada Tahun 2014. } \\
\text { Magister Kesehatan Masyarakat diperoleh dari Universitas Sari Mutiara Indonesia, } \\
\text { Jurusan Komite Akreditasi Rumah Sakit (KARS) pada Tahun 2017. Saat ini aktif } \\
\text { sebagai pengajar di Program Studi D-IV Manajemen Informasi Kesehatan Universitas } \\
\text { Imelda Medan. }\end{array}$ \\
\hline & $\begin{array}{l}\text { Khairani, Gelar D-III diperoleh dari Akademi Kebidanan Mitra Husada Medan, } \\
\text { Jurusan Kebidanan pada tahun 2013. Gelar D-IV diperoleh dari Universitas Respati } \\
\text { Yogyakarta, Jurusan Bidan Pendidik Tahun 2014. Magister Kesehatan Masyarakat } \\
\text { diperoleh dari Universitas Respati Indonesia, Jurusan Kesehatan Masyarakat dengan } \\
\text { Konsentrasi Kesehatan Reproduksi pada tahun 2017. Saat ini aktif sebagai dosen tetap } \\
\text { di Prodi DIII Perekam Dan Informasi Kesehatan Universitas Imelda Medan dan } \\
\text { Sebagai Dosen tetap. }\end{array}$ \\
\hline
\end{tabular}

